\title{
Surface Faceting and Reconstruction of Ceria Nanoparticles
}

Chengwu Yang, ${ }^{[a]}$ Xiaojuan Yu, ${ }^{[a]}$ Stefan Heißler, ${ }^{[a]}$ Alexei Nefedov, ${ }^{[a]}$ Sara Colussi, ${ }^{[b]}$ Jordi Llorca, ${ }^{[c]}$ Alessandro Trovarelli, ${ }^{[b]}$ Yuemin Wang, ${ }^{*[a]}$ and Christof Wöll*[a]

\begin{abstract}
The surface atomic arrangement of metal oxides strongly determines their physical and chemical properties, and the ability to control and optimize structural parameters is of crucial importance for many applications, in particular in heterogeneous catalysis and photocatalysis. While for macroscopic single crystals such structure determinations can be carried out using established methods, for nanoparticles (NPs) this is a challenging task. Here, we report the results of a study where CO is used as a probe molecule to determine the structure of surfaces exposed by rod-shaped ceria NPs. After calibrating the $\mathrm{CO}$ stretch frequencies using results obtained for different ceria single crystal surfaces we find that the rod-shaped NPs actually restructure and expose $\{111\}$ nanofacets. This finding has important consequences for understanding the controversial surface chemistry of these catalytically highly active ceria NPs and paves the way for a predictive, rational design of catalytic materials at nanoscale.
\end{abstract}

Metal oxides represent one of the most important and widely employed classes of solid catalysts. ${ }^{[1]}$ Due to the lower coordination number of metal centers in oxides than in bulk metals and the need for charge balancing at their surfaces, many oxide surfaces tend to undergo rearrangement and reconstruction..$^{[2]}$ These structural changes often cause substantial modifications in surface chemistry and catalysis.

[a]Dr. C. Yang, X. Yu, S. Heißler, Dr. A. Nefedov, Dr. Y. Wang, Prof. Dr. Ch. Wöll

Institute of Functional Interfaces. Karlsruhe Institute of Technology

76344 Eggenstein-Leopoldshafen (Germany)

E-mail: yuemin.wang@kit.edu,christof.woell@kit.edu

[b]Dr. S. Colussi, Prof. Dr. A. Trovarelli

Dipartimento Politecnico. Università di Udine

108-33100 Udine (Italy)

[c]Prof. Dr. J. Llorca

Institut de Tècniques Energètiques and Centre for Research in Nanoengineering. Universitat Politècnica de Catalunya

808028 Barcelona (Spain)
Cerium oxide $\left(\mathrm{CeO}_{2}\right)$ has been extensively utilized in various catalytic reactions, either as catalyst or as support material. ${ }^{[3]}$ It is known to exhibit strong structure-activity relationships and shows excellent redox properties as well as an unusually high oxygen storage capacity (OSC). Recently, $\mathrm{CeO}_{2}$ nanocrystals with controlled morphologies such as nanopolyhedra, nanorods and nanocubes have been fabricated. ${ }^{[4]}$ The synthesized $\mathrm{CeO}_{2}$ nanostructures exhibit very different catalytic activities for $\mathrm{CO}$ oxidation, and a general trend following the sequence: rods $>$ cubes $>$ octahedra has been found. ${ }^{[4 b-e]}$ Surface faceting has been detected for ceria nanopowders ${ }^{[5]}$ and nanocubes ${ }^{[6]}$ by transmission electron microscopy (TEM). However, for nanoparticles (NPs), TEM is often not sufficient to image the precise atomic arrangement, and providing a satisfying relation of NP surface chemistry to that of the corresponding bulk materials has so far not been possible. The surface chemistry of $\mathrm{CeO}_{2}(111)$ single-crystals has been the subject of a number of experimental works. ${ }^{[7]}$ However, much less information is available for the catalytically most active $\mathrm{CeO}_{2}(110)$ surface. ${ }^{[8]}$ As regards ceria NP surfaces, a fairly large number of IRstudies for the powder materials exposed to CO have been reported..$^{[9]}$ Unfortunately, a reliable assignment of $\mathrm{CO}$ vibrational frequencies to specific surface orientations has been virtually impossible due to the lack of reference data for $\mathrm{CO}$ adsorbed on welldefined ceria single crystal surfaces. Consequently, a detailed atomic-scale understanding of complex nanostructured ceria is still missing, which makes the fabrication and engineering of these systems largely empirical.

Here, we present a thorough surface-science study on macroscopic $\mathrm{CeO}_{2}(110)$ single-crystals as well as ceria nanorods predominantly exposing (110) terminations. In combination with grazing emission $x$-ray photoelectron spectroscopy (XPS) and low energy electron diffraction (LEED), the first application of infrared reflection-absorption spectroscopy (IRRAS) to this surface allowed to demonstrate that the CO stretch frequency is very well suited to monitor the atomic structure evolution of $\mathrm{CeO}_{2}(110)$ under 
different reduction conditions. On the basis of the polarization-dependent IRRAS data recorded for $\mathrm{CeO}_{2}$ single crystals, we provided direct spectroscopic evidence for the presence of a large amount of $\{111\}$ type nanofacets formed on (110) planes of active ceria nanorods. The atomic surface structure of ceria nanorods is further corroborated by high-resolution TEM (HRTEM).

The stoichiometric, ideal bulk truncated $(1 \times 1)$ structure of the ceria (110) surface (Figure 1a) consists of two $\mathrm{O}$ rows with a row of $\mathrm{Ce}$ running along the [110] direction and is characterized by a well-defined LEED diffraction pattern (Figure 2b). Figure 2a shows IRRAS data recorded for this oxidized $\mathrm{CeO}_{2}$ (110) exposed to $\mathrm{CO}$ at $80 \mathrm{~K}$. The $\mathrm{p}$-polarized spectrum exhibits a predominant peak at $2170 \mathrm{~cm}^{-1}$, which is assigned to $\mathrm{CO}$ bound to $\mathrm{Ce}^{4+}$ cations embedded in a perfect single crystalline surface environment.

After annealing at $800 \mathrm{~K}$ under UHV conditions (in the absence of $\mathrm{O}_{2}$ ), the well-defined ( $1 \times 1$ ) LEED pattern of the ideally terminated $\mathrm{CeO}_{2}(110)$ single-crystal surface changes to a clear, equally well-defined $(2 \times 1)$ LEED pattern (Figure $2 b$ ), revealing a new surface atomic arrangement. A general consensus on the precise geometric structure of this reduced phase has not yet been achieved. A tentative model based on the reduction of surface $\mathrm{O}$-species as evidenced by the XPS-data (see below) is shown in Figure $1 \mathrm{~b}$. According to this model, the $\mathrm{CeO}_{2}(110)$ surface is reconstructed with $25 \%$ oxygen atoms being missing. This structure thus resembles a layer of $\mathrm{Ce}_{2} \mathrm{O}_{3}$, and is supported by the XPS data discussed below. For this $(2 \times 1)$ reconstruction, adsorbed $\mathrm{CO}$ shows only one sharp $\mathrm{CO}$ band at $2175 \mathrm{~cm}^{-1}$ (Figure 2a), which is attributed to $\mathrm{CO}$ species adsorbed at $\mathrm{Ce}^{3+}$ ions. Note, that the $\mathrm{Ce}^{3+}$ related $\mathrm{CO}$ band at $2178 \mathrm{~cm}^{-1}$ was also observed on the $(1 \times 1)$ surface as a minority species (Figure $2 a)$. The thermal desorption IRRAS data (Figure S1, see supporting information) show that upon annealing the $2170 \mathrm{~cm}^{-1}$ band decreases quickly in intensity and disappears at $95 \mathrm{~K}$, while the $2178 \mathrm{~cm}^{-1}$ band is found to desorb at $110 \mathrm{~K}$ (Figure $2 \mathrm{c}$ ). The corresponding calculated binding energies were $0.28 \mathrm{eV}$ and $0.32 \mathrm{eV}$, respectively, revealing a stronger interaction between $\mathrm{CO}$ and the reduced $\mathrm{Ce}^{3+}$ sites.

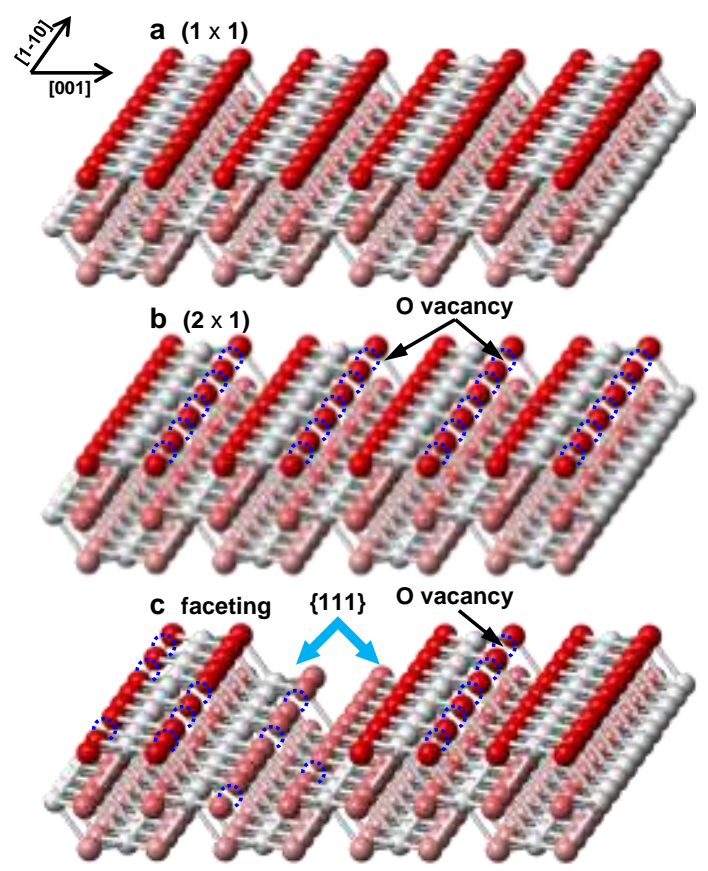

Figure 1. Structure evolution during reduction of the $\mathrm{CeO}_{2}(110)$ surface. a) The stoichiometric, fully oxidized $(1 \times 1)$ phase. b) $(2 \times 1)$ reconstruction. c) $\{111\}$ nanofaceting. The oxygen vacancies are indicated by the dashed circles.

Interestingly, subjecting the $\mathrm{CeO}_{2}(110)$ surface to repeated cycles of sputtering and annealing leads to further substantial changes, as evidenced by the IRRAS-data reproduced in Figure S2 and Figure 3. At the lowest CO coverage, the main band is located at $2170 \mathrm{~cm}^{-1}$ with a shoulder at $2178 \mathrm{~cm}^{-1}$, which is assigned to $\mathrm{CO}$ bound to perfect and defective sites on the (110) terrace, respectively. As the CO coverage increases, two low-lying features emerge at 2154 and $2163 \mathrm{~cm}^{-1}$ which are characteristic for CO species adsorbed at oxidized and defective sites of $\{111\}$ facets. ${ }^{[7 \mathrm{~h}]}$ They become dominant at saturation coverage, indicating that most parts of the surface expose the low energy $\{111\}$ facets. Figure 3 shows the corresponding deconvoluted IRRAS spectra. The simultaneous observation of four $\mathrm{CO}$ bands in the $\mathrm{p}$ polarized spectrum reveals unambiguously the reconstruction of the reduced $\mathrm{CeO}_{2-x}(110)$ surface 
leading to the coexistence of partially reduced (110) terrace and $\{111\}$ nanofacets.

In order to identify the adsorption geometry of various $\mathrm{CO}$ species, we have performed additional IRRAS experiments recorded with s-polarized light (Figure 3). The s-polarized light is oriented parallel to the surface and perpendicular to the incidence direction. Only vibrational modes with a transition dipole moment (TDM) orientated parallel to the surface can be excited by s-polarized light resulting in negative absorbance bands. In the s-polarized spectra (Figure 3), only two CO bands located at 2154 and $2163 \mathrm{~cm}^{-1}$ originating from $\mathrm{CO}$ adsorbed on (111) surfaces are detected. This observation is in perfect agreement with the fact that the $\{111\}$ nanofacets are tilted with respect to the surface plane (see Figure 1c). As a result, $\mathrm{CO}$ molecules bound to this surface adopt an effectively tilted geometry with respect to the normal of the substrate, and therefore show a weak signal also in the s-polarized spectra. In contrast, no CO bands assigned to (110) terraces were visible with s-polarized light, indicating that $\mathrm{CO}$ adsorbs to the (110) terrace in an upright orientation (see Figure 2a).
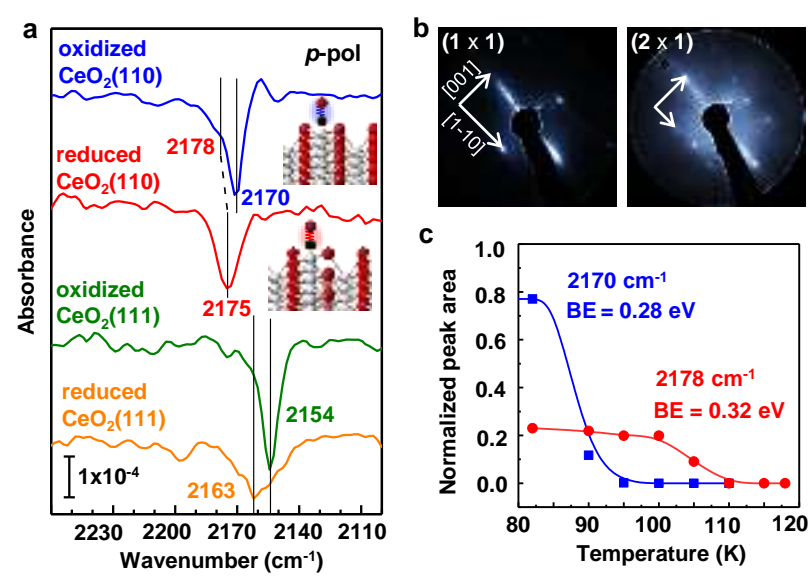

Figure 2. Surface structure of flat $\mathrm{CeO}_{2}(110)$. a) IRRA spectra of $1 \mathrm{MLCO}$ adsorption on oxidized (blue line) and reduced (red line) ceria (110) at $80 \mathrm{~K}$ with $\mathrm{p}$ polarized light incident along the [110] $]$ azimuth. $\mathbf{b}$ ) LEED patterns of oxidized and reduced (110) surfaces. c) Integrated intensity evolution of two spectral components with increasing temperatures. For comparison, the IRRAS data of $1 \mathrm{MLCO}$ adsorption on oxidized and reduced $\mathrm{CeO}_{2}(111)^{[\mathrm{fh}]}$ are shown in (a).

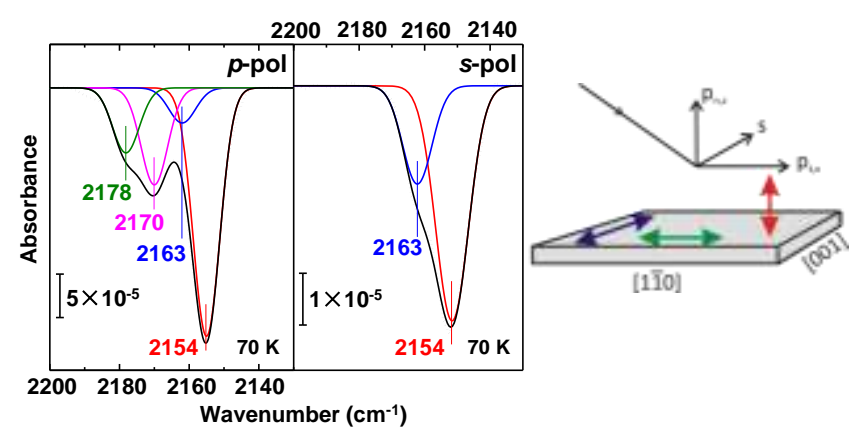

Figure 3. $\mathrm{CeO}_{2}(110)$ surface faceting probed by IRRAS after $\mathrm{CO}$ adsorption. Fitting of $\mathrm{p}$ - and s-polarized spectra of faceted $\mathrm{CeO}_{2}(110)$ exposed to $\mathrm{CO}$ at $70 \mathrm{~K}$ with light incident along the [1싱] azimuth.

The present IRRAS data provide the first direct spectroscopic evidence for the atomic structure evolution of $\mathrm{CeO}_{2}$ (110) from the ideally terminated $(1 \times 1)$ surface over a $(2 \times 1)$-reconstruction to a $\{111\}$ faceted surface upon reduction of the substrate. The corresponding loss of surface $O$ atoms can be nicely monitored by the grazing-emission XPS data (Figure $4)$, which are extremely surface sensitive. The $\mathrm{Ce} 3 \mathrm{~d}$ core-level spectra are presented in Figure 4a. The spin-orbit components with unprimed labels, $v$ and $u$, correspond to the primary $\mathrm{Ce} 3 \mathrm{~d}_{5 / 2}$ and $\mathrm{Ce} 3 \mathrm{~d}_{5 / 2}$ states, while other doublets represent satellite features arising from the $\mathrm{Ce} 3 \mathrm{~d}_{5 / 2}$ and $3 d_{3 / 2}$ ionization. ${ }^{[10]}$ The doublets labeled $v_{0} / u_{0}$ and $v^{\prime} / u^{\prime}$ are characteristic for the $\mathrm{Ce}^{3+}$ species. On the basis of the Ce $3 d$ XPS data, the $(1 \times 1)$ surface possesses about 10 $\% \mathrm{Ce}^{3+}$. The corresponding $\mathrm{O} 1 \mathrm{~s}$ spectrum shows an intense peak at $529.4 \mathrm{eV}$ originating from lattice oxygen anions in the regular $\mathrm{CeO}_{2}$ coordination and a weak component at $531.1 \mathrm{eV}(7 \%)$ which is assigned to oxygen anions located near to $O$ vacancy sites in reduced $\mathrm{CeO}_{2-x .}{ }^{[11]}$ The XPS data reveal that a small amount of surface $O$ vacancies are formed on the $(1 \times 1)$ surface, in line with the IR results (Figure 2a). 

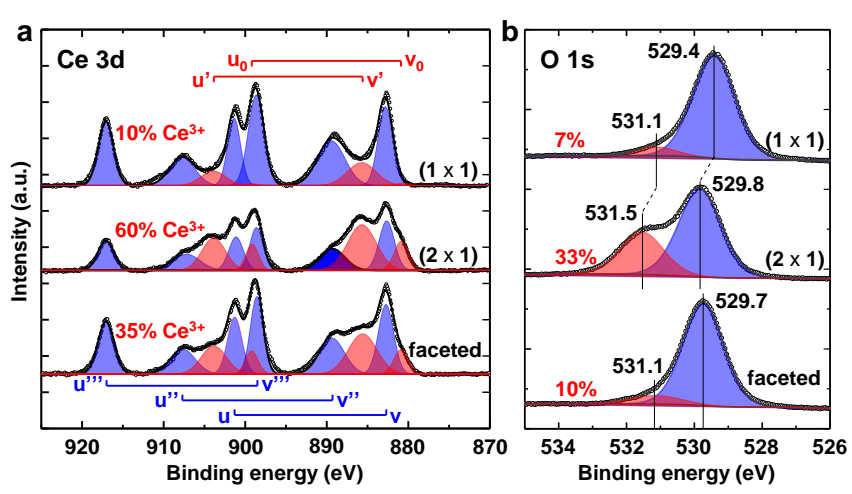

Figure 4. Grazing emission XPS characterization of $\mathrm{CeO}_{2}(110)$. Fitting of core-level a) Ce3d and b) O1s grazing emission XP spectra of oxidized, reduced and faceted ceria (110) surfaces.

The $\mathrm{Ce}^{3+}$ density on the $(2 \times 1)$ reconstructed surface is as high as approximately $60 \%$ (Figure 4). Accordingly, the concentration of the $\mathrm{O} 1 \mathrm{~s}$ peak at $531.5 \mathrm{eV}$ increases largely to $33 \%$ (note that one $O$ vacancy creates two $\mathrm{Ce}^{3+}$ species). Interestingly, we found it difficult to re-oxidize this highly reduced, reconstructed $(2 \times 1)$ surface layer. Even after several cycles of annealing in oxygen atmosphere $\left(1 \times 10^{-6}\right.$ mbar) at $800 \mathrm{~K}$ there are still ca. $30 \% \mathrm{Ce}^{3+}$ ions left on the surface (see Figure S3). It thus appears that this reduced surface acts as a passivation layer as regards re-oxidation. According to previous theoretical work, ${ }^{[12]}$ upon O-vacancy formation by removing an $\mathrm{O}$ from the ceria (110) surface the adjacent $O$ atom moves toward that vacancy into a bridge site between two Ce cations and then a split O-vacancy is produced (see Figure 1b). Therefore, upon re-oxidation, the new $\mathrm{O}$-atoms need to overcome a repulsive barrier since the oxygen anions at the bridge sites need to move back to their original positions.

Importantly, further annealing the $(2 \times 1)$ surface at 800 ? $850 \mathrm{~K}$ does not create more $\mathrm{O}$ vacancy sites, but instead leads to a significant decrease of both $\mathrm{Ce}^{3+}(35$ $\%)$ and defect-related $\mathrm{O}(10 \%)$ populations. These findings are in good agreement with the proposed occurrence of surface faceting. The reduced $\mathrm{Ce}^{3+}$ cations with lowered coordination numbers are likely to become instable with further removing $O$ atoms on the $(2 \times 1) \mathrm{CeO}_{2}(110)$ surface. Consequently, surface faceting occurs to form a large number of low-energy \{111\}-type nanofacets (Figure 1c). Interestingly, the \{111\}-faceting leads to a larger decrease in concentration of defect-related $\mathrm{O}$ at $\sim 531.1 \mathrm{eV}$ compared to the $\mathrm{Ce}^{3+}$ species. This unexpected finding suggests that the $531.1 \mathrm{eV}$ peak results only from $\mathrm{O}$ vacancy sites formed on (110) terraces, where the coordination environment of neighboring $\mathrm{O}$ atoms is modified (see Figure 1b). ${ }^{[12]}$ In comparison, the oxygen anions located near to $O$ vacancies at $\{111\}$ facets are much less perturbed (see Figure 1c). Indeed, this $01 \mathrm{~s}$ peak was not observed for reduced $\mathrm{CeO}_{2}(111)$ singlecrystal surfaces.

The above results collected on various $\mathrm{CeO}_{2}$ single crystal surfaces were used to characterize the complex and controversial surface structure of ceria nanorods. It has been proposed that ceria rods expose (100) and (110) surfaces and grow along the [110] direction..$^{[\mathrm{a}, 4 \mathrm{bb}]}$ However, more recently, it was suggested that ceria rods can also expose (111) surfaces as well as a small portion of (100) facets. ${ }^{[13]}$ Here, on the basis of IRRAS results for various $\mathrm{CeO}_{2}$ single crystal surfaces, we demonstrate that $\mathrm{CO}$ can be used as probe molecule to settle the discrepancy as regards the atomic surface structure of ceria rods.

UHV-FTIR measurements of $\mathrm{CO}$ adsorption were performed at $60 \mathrm{~K}$ on the ceria nanorods pre-heated at $723 \mathrm{~K}$. The corresponding results are shown in Figure $5 \mathrm{a}$. After exposure to $\mathrm{CO}$, two intense $\mathrm{CO}$ bands are clearly observed at 2170 and $2152 \mathrm{~cm}^{-1}$. With reference to our results of $\mathrm{CO}$ adsorption on ceria single crystals summarized in Figure 2a, these two components can be assigned in a straightforward fashion to $\mathrm{CO}$ on $\mathrm{Ce}^{4+}$ sites of (110) and (111) faces, respectively. Additionally, a weak IR band around $2140 \mathrm{~cm}^{-1}$ is resolved, which is assigned to CO multilayers formed at temperatures as low as $60 \mathrm{~K}$.

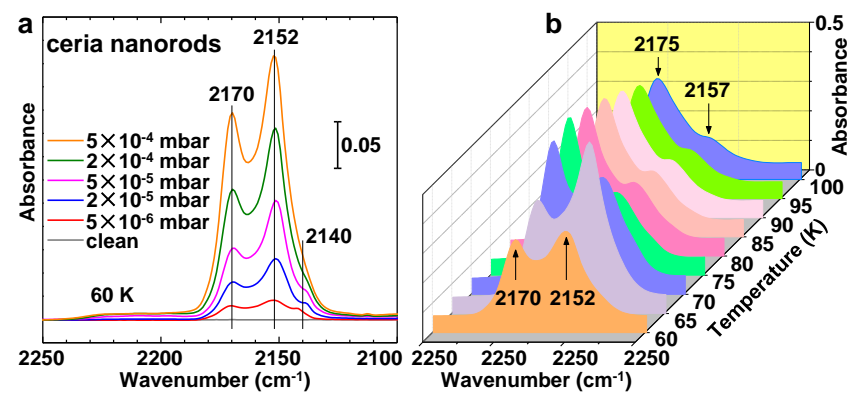


Figure 5. Surface structure of ceria nanorods probed by IR after CO adsorption. a) UHV-FTIR spectra recorded after exposing the ceria nanorods to different doses of $\mathrm{CO}$ at $60 \mathrm{~K}$ and $\mathbf{b}$ ) subsequently heating to higher temperatures.

Figure $5 \mathrm{~b}$ shows the corresponding temperaturedependent IR spectra. Surprisingly, instead of the expected decrease, the intensities of $\mathrm{CO}$ bands become larger upon heating to $65 \mathrm{~K}$, indicating a restructuring process of the adsorbed $\mathrm{CO}$ layer from non-uniform distribution at extremely low temperature $(60 \mathrm{~K})$ to a more homogeneous molecular environment and thereby an increase in ordering. Upon further annealing the $\mathrm{CO}$ band at 2152 $\mathrm{cm}^{-1}$ gradually decreases in intensity, while the 2170 $\mathrm{cm}^{-1}$ band increase with heating to $75 \mathrm{~K}$. This finding suggests a thermal diffusion of adsorbed $\mathrm{CO}$ species from $\{111\}$ nanofacets to (110) terraces, in line with the observation for $\mathrm{CO}$ adsorption on faceted $\mathrm{CeO}_{2}(110)$ single crystal surfaces as reported in Figure S4. Further heating leads to desorption of $\mathrm{CO}$ molecules, as demonstrated by the attenuation of both $\mathrm{CO}$ bands and their blue-shift in frequency. Overall, on the basis of the IRRAS data obtained for various $\mathrm{CeO}_{2}$ single crystal surfaces, the $\mathrm{CO}$ bands observed on ceria nanorods can be unambiguously assigned, which provides direct spectroscopic evidence that the ceria nanorods expose a large amount of (111)-oriented surface regions resulting from a faceting of the (110) plane.

The surface structure of the ceria nanorods was further characterized by recording high-resolution TEM images. The image reproduced in Figure 6a shows several nanorods measuring about 0.5 ? 2 ?m in length and 20080 $\mathrm{nm}$ in width. The surface of the nanorods is decorated by clumps of much smaller nanoparticles (about 5 国 $10 \mathrm{~nm}$ ). Such inhomogeneities are common observation in TEM images of ceria nanorods. ${ }^{[14]}$
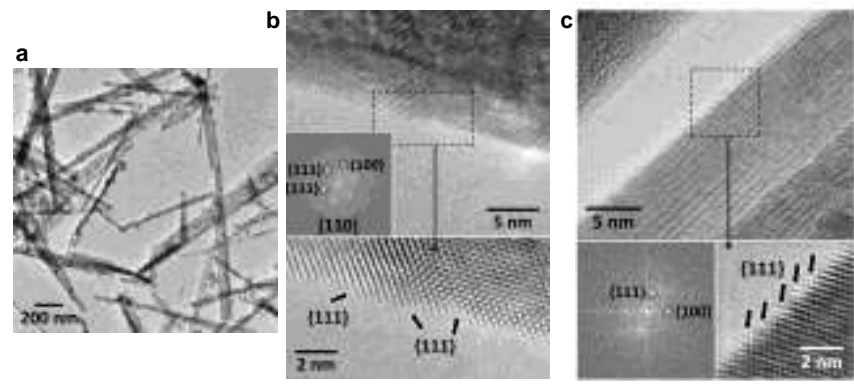

Figure 6. Surface structure of ceria nanorods characterized by HRTEM. a) A general view of rodshaped $\mathrm{CeO}_{2}$ nanoparticles and $\mathbf{b}, \mathbf{c}$ ) highmagnification HRTEM images of $\mathrm{CeO}_{2}$ nanorods showing clearly $\{111\}$-facets formed on the (110) plane.

In Figure $6 b$, a portion of a ceria nanorod TEM image is shown along with the corresponding Fourier Transform (FT) image. Spots at 3.12 and $2.71 \AA$ correspond to the (111) and (200) (\{100\}-type) crystallographic planes of ceria, respectively. Clearly, the ceria nanorod is oriented along the [110] crystallographic direction. In the detailed view at atomic scale of the surface corresponding to the area enclosed in the black rectangle, it is seen that the surface is not completely flat. Several atoms are missing, so that new "nanofacets" are exposed. In all cases, these nanofacets correspond to the $\{111\}$-type orientation. Some of the $\{111\}$-type nanofacets are indicated by arrows in Figure 6b. Another example of nanofaceting is shown in Figure 6c. Again, the surface of the nanorods is not completely flat and \{111\}-type facets can be identified, as marked by arrows in the enlarged image. From the TEM-images it is difficult to assess the exact amount of surface area planes exposed by the differently oriented surface facets, but it is clear that in addition to (110) and (100) terminations, ceria nanorods also expose a large amount of (111) terminations, mostly in the form of nanofacets formed on the (110) plane.

In summary, we have presented, for the first time, a thorough IRRAS study on the atomic structure evolution of the catalytically most active $\mathrm{CeO}_{2}(110)$ single-crystal surface. By calibrating the stretch frequency of adsorbed $\mathrm{CO}$ for various single crystal surfaces, we are able to demonstrate that the rod- 
shaped ceria NPs which previously were assumed to expose a (110)-terminated surface essentially restructure and the $\{111\}$-type faceting is an intrinsic property of the ceria (110) surface. Consequently, this particularly interesting type of ceria NPs exhibits a rather complex surface structure exposing various defects (sawtooth-like nanofacets, O vacancies, edges and corners), which could be responsible for the higher activity generally observed in rod-shaped ceria NPs. ${ }^{[4 b-e]}$ In particular, nanofaceting can help in anchoring noble metals on the ceria surface which has been found to significantly improve catalytic properties of $\mathrm{CeO}_{2}$-supported Au catalysts. ${ }^{[6 \mathrm{bb}]}$ Overall, we believe that these results are an important step forward to allow the tuning and control of the surface structure and reactivity of ceria-based materials under different atmospheres.

\section{Acknowledgements}

The funding from the "Science and Technology of Nanosystems" Programme (Project No. 432202) is gratefully acknowledged. C.Y. and X.Y. are grateful for PhD fellowships donated by the China Scholarship Council (CSC). C.Y. thanks the Helmholtz Research School "Energy-related catalysis" for financial support. J.L. is Serra Húnter Fellow and is grateful to ICREA Academia program and MINECO/FEDER grant ENE2015-63969-R. S.C. and A.T. thank MIUR and Regione FVG for financial support.

[1] S. D. Jackson, J. S. J. Hargreaves, Metal Oxide Catalysis, Wiley-VCH, Weinheim, 2009.

[2] a) H.-J. Freund, H. Kuhlenbeck, V. Staemmler, Rep. Prog. Phys. 1996, 59, 283-347; b) U. Diebold, Surf. Sci. Rep. 2003, 48, 53-229; c) C. Wöll, Prog. Surf. Sci. 2007, 82, 55-120.

[3] a) A. Trovarelli, Catal. Rev. Sci. Eng. 1996, 38, 439-520; b) A. Trovarelli, P. Fornasiero, Catalysis by Ceria and Related Materials, Imperial College Press, 2013; c) T. Montini, M. Melchionna, M. Monai, P. Fornasiero, Chem. Rev. 2016, 116, 5987-6041; d) M. V. Ganduglia-Pirovano, A. Hofmann, J. Sauer, Surf. Sci. Rep. 2007, 62, 219-270; e) J. Paier, C. Penschke, J. Sauer, Chem. Rev. 2013, 113, 3949-3985; f) W. Huang, Y. Gao, Catal. Sci. Technol. 2014, 4, 3772-3784; g) L.
Vivier, D. Duprez, ChemSusChem 2010, 3, 654-678; h) D. R. Mullins, Surf. Sci. Rep. 2015, 70, 42-85; i) C. Sun, H. Li, L. Chen, Energy Environ. Sci. 2012, 5, 8475-8505; j) N. J. Divins, I. Angurell, C. Escudero, V. Pérez-Dieste, J. Llorca, Science 2014, 346, 620-623; k) E. Aneggi, M. Boaro, S. Colussi, C. de Leitenburg, A. Trovarelli, in Handbook on the Physics and Chemistry of Rare Earths, Elsevier, 2016.

[4] a) H.-X. Mai, L.-D. Sun, Y.-W. Zhang, R. Si, W. Feng, H.-P. Zhang, H.-C. Liu, C.-H. Yan, J. Phys. Chem. B 2005, 109, 24380-24385; b) K. Zhou, X. Wang, X. Sun, Q. Peng, Y. Li, J. Catal. 2005, 229, 206-212; c) Tana, M. Zhang, J. Li, H. Li, Y. Li, W. Shen, Catal. Today 2009, 148, 179-183; d) Z. Wu, M. Li, S. H. Overbury, J. Catal. 2012, 285, 61-73; e) Z. Hu, X. Liu, D. Meng, Y. Guo, Y. Guo, G. Lu, ACS Catal. 2016, 6, 2265-2279; f) Z. Wu, M. Li, J. Howe, H. M. Meyer, S. H. Overbury, Langmuir 2010, 26, 16595-16606; g) D. Zhang, X. Du, L. Shi, R. Gao, Dalton Trans. 2012, 41, 14455-14475; h) K. Zhou, Y. Li, Angew. Chem. Int. Ed. 2012, 51, 602-613; i) Y. Li, W. Shen, Chem. Soc. Rev. 2014, 43, 1543-1574.

[5] P. A. Crozier, R. Wang, R. Sharma, Ultramicroscopy 2008, 108, 1432-1440.

[6] a) Y. Lin, Z. Wu, J. Wen, K. R. Poeppelmeier, L. D. Marks, Nano Lett. 2014, 14, 191-196; b) M. Tinoco, S. Fernandez-Garcia, M. Lopez-Haro, A. B. Hungria, X. Chen, G. Blanco, J. A. Perez-Omil, S. E. Collins, H. Okuno, J. J. Calvino, ACS Catal. 2015, 5, 3504-3513.

[7] a) H. Nörenberg, G. Briggs, Phys. Rev. Lett. 1997, 79, 4222; b) H. Nörenberg, G. A. D. Briggs, Surf. Sci. 1999, 424, L352-L355; c) Y. Namai, K.-i. Fukui, Y. Iwasawa, J. Phys. Chem. B 2003, 107, 11666-11673; d) Y. Namai, K.-i. Fukui, Y. Iwasawa, Catal. Today 2003, 85, 79-91; e) F. Esch, S. Fabris, L. Zhou, T. Montini, C. Africh, P. Fornasiero, G. Comelli, R. Rosei, Science 2005, 309, 752-755; f) S. Torbrügge, M. Reichling, A. Ishiyama, S. Morita, Ó. Custance, Phys. Rev. Lett. 2007, 99, 056101; g) S. Gritschneder, M. Reichling, J. Phys. Chem. C 2008, 112, 2045-2049; h) C. Yang, L.-L. Yin, F. Bebensee, M. Buchholz, H. Sezen, S. Heissler, J. Chen, A. Nefedov, H. Idriss, X.-Q. Gong, C. Wöll, Phys. Chem. Chem. Phys. 2014, 16, 24165-24168. 
[8] a) H. Nörenberg, G. A. D. Briggs, Surf. Sci. 1999, 433-435, 127-13; b) C. Yang, F. Bebensee, A. Nefedov, C. Wöll, T. Kropp, L. Komissarov, C. Penschke, R. Moerer, J. Paier, J. Sauer, J. Catal. 2016, 336, 116-125.

[9] a) M. I. Zaki, B. Vielhaber, H. Knoezinger, J. Phys. Chem. 1986, 90, 3176-3183; b) C. Li, Y. Sakata, T. Arai, K. Domen, K.-i. Maruya, T. Onishi, J. Chem. Soc., Faraday Trans. 1 1989, 85, 929-943; c) C. Binet, M. Daturi, J.-C. Lavalley, Catal. Today 1999, 50, 207225; d) R. Farra, S. Wrabetz, M. E. Schuster, E. Stotz, N. G. Hamilton, A. P. Amrute, J. Perez-Ramirez, N. Lopez, D. Teschner, Phys. Chem. Chem. Phys. 2013, 15, 3454-3465; e) S. Agarwal, X. Zhu, E. J. M. Hensen, B. L. Mojet, L. Lefferts, J. Phys. Chem. C 2015, 119, 1242312433.

[10] P. Burroughs, A. Hamnett, A. F. Orchard, G. Thornton, J. Chem. Soc., Dalton Trans. 1976, 16861698.

[11] a) J. P. Holgado, G. Munuera, J. P. Espinós, A. R. González-Elipe, Appl. Surf. Sci. 2000, 158, 164-171; b) M. A. Henderson, C. L. Perkins, M. H. Engelhard, S. Thevuthasan, C. H. F. Peden, Surf. Sci. 2003, 526, 1-
18; c) G. D. Wang, D. D. Kong, Y. H. Pan, H. B. Pan, J. F. Zhu, Appl. Surf. Sci. 2012, 258, 2057-2061; d) V. Stetsovych, F. Pagliuca, F. Dvořák, T. Duchoň, M. Vorokhta, M. Aulická, J. Lachnitt, S. Schernich, I. Matolínová, K. Veltruská, T. Skála, D. Mazur, J. Mysliveček, J. Libuda, V. Matolín, J. Phys. Chem. Lett. 2013, 4, 866-871.

[12] a) Z. Cheng, B. J. Sherman, C. S. Lo, J. Chem. Phys. 2013, 138, 014702; b) N. M. Galea, D. O. Scanlon, B. J. Morgan, G. W. Watson, Mol. Simul. 2009, 35, 577-583; c) J. Kullgren, K. Hermansson, C. Castleton, J. Chem. Phys. 2012, 137, 044705.

[13] a) N. Ta, J. Liu, S. Chenna, P. A. Crozier, Y. Li, A. Chen, W. Shen, J. Am. Chem. Soc. 2012, 134, 2058520588; b) S. Agarwal, L. Lefferts, B. L. Mojet, D. A. J. M. Ligthart, E. J. M. Hensen, D. R. G. Mitchell, W. J. Erasmus, B. G. Anderson, E. J. Olivier, J. H. Neethling, A. K. Datye, ChemSusChem 2013, 6, 1898-1906.

[14] a) E. Aneggi, D. Wiater, C. de Leitenburg, J. Llorca, A. Trovarelli, ACS Catal., 2014, 4, 172-181; b) T. Désaunay, G. Bonura, V. Chiodo, S. Freni, J. P. Couzinié, J. Bourgon, A. Ringuedé, F. Labat, C. Adamo, M. Cassir, J. Catal. 2013, 297, 193-201. 
